\title{
Overweight and blood pressure: results from the examination of a selected group of adolescents in northern Italy
}

\author{
G Turconi ${ }^{1, *}$, L Maccarini $^{2}$, R Bazzano $^{1}$ and C Roggi ${ }^{1}$ \\ 'Department of Applied Health Sciences, Section of Human Nutrition and Dietetics, University of Pavia, \\ Via Bassi 21, I-27100 Pavia, Italy: ${ }^{2}$ Department of Preventive, Occupational and Community Medicine, \\ Hygiene Institute, Pavia, Italy
}

Submitted 22 February 2007: Accepted 9 September 2007: First published online 16 November 2007

\begin{abstract}
Objective: The aim of the present study was to investigate blood pressure (BP) levels and their relationship with different indices of body fat in a group of adolescents, in order to evaluate the prevalence of hypertension and plan preventive and corrective strategies.

Design: Cross-sectional study in primary care.

Setting: All high schools in the Aosta Valley region, northern Italy.

Subjects: Five hundred and thirty-two adolescents of both sexes, aged 15.4 (standard deviation 0.7 ) years. The following parameters were measured: body weight, body height, body mass index (BMI), four skinfold thicknesses, body fat mass, waist and hip circumferences and BP.

Results: BMI data indicated a high prevalence of overweight subjects in both sexes, but higher in males, while the prevalence rate of obese adolescents was lower. Of the total, $11 \cdot 8 \%$ of subjects suffered from systolic hypertension, while $6.9 \%$ suffered from diastolic hypertension. In linear correlation analysis, BMI and all adiposity indices, except waist:hip ratio, were found to be significantly associated ( $P$ ranging between 0.05 and 0.001) with both systolic BP and diastolic BP in both sexes, with $r$ ranging between 0.152 and 0.359 . Multiple regression analysis with the stepwise method showed BMI and body fat mass to have the strongest association $(P<0 \cdot 001)$ with BP, with $r$ ranging between 0.275 and 0.359 .

Conclusion: Unless reversed, these conditions are worrying and predict the possible development of cardiovascular disease in adulthood. There is a pressing need to develop a comprehensive medical and nutrition plan, together with preventive and corrective strategies, in school programmes.
\end{abstract}

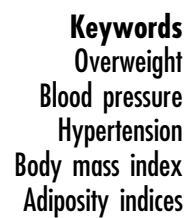

Keywords

Overweight

ood pressure

Body mass index

Adiposity indices
The prevalence of overweight and obesity in childhood and adolescence is increasing rapidly worldwide ${ }^{(1-3)}$. Epidemiological data show that prevalence rates are increasing not only in industrialised countries but also in developing countries ${ }^{(4)}$, especially as far as the adolescent population is concerned. In general, prevalence rates are higher in adolescents than in children ${ }^{(5)}$, and are also higher among males than females. Overweight and obesity at a young age predicts the likelihood of obesity in adulthood $^{(6)}$.

Overweight and obesity at a young age are important risk factors for several disorders ${ }^{(7)}$ such as hypertension ${ }^{(8,9)}$, early atherosclerotic damage ${ }^{(10)}$, cardiovascular disease ${ }^{(11-13)}$, metabolic syndrome ${ }^{(14)}$, the onset of non-insulin-dependent diabetes mellitus ${ }^{(15)}$ as well as morbidity and mortality in later life $\mathrm{e}^{(16,17)}$

The importance of measuring blood pressure (BP) in childhood has been widely recognised, given that elevated BP levels at a young age may be predictive of early signs of essential hypertension in adulthood. Careful measurements of BP and thorough evaluation of adolescents with sustained high BP should make it possible to identify those who require treatment.

Even though BP levels are positively correlated with height, most authors agree that body mass index (BMI) contributes significantly to BP variability and is the best predictor of BP values ${ }^{(18-21)}$. In a sample of 155 Native American youths aged 5-18 years, Smith and Rinderknecht $^{(22)}$ showed that mean systolic blood pressure (SBP) and diastolic blood pressure (DBP) increased with increasing BMI percentile. Martinez et al. ${ }^{(23)}$ revealed a $0.83 \mathrm{mmHg}$ increment in BP for each unit increment of BMI in a sample of 2115 secondary-school students aged 14.8 (standard deviation, sD 1.6) years.

In a sample of 2365 healthy schoolchildren aged 8-16 years, Reich et al. ${ }^{(24)}$ showed a significant trend towards a 
higher prevalence of hypertension in subjects with high BMI, but the positive correlation of hypertension to BMI was not only caused by overweight subjects. Indeed, when the high-risk group (above the 90th percentile) was excluded, the trend remained significant. In addition, in a case-control study on 1322 Chinese boys and girls aged 0.1-6.9 years, He et al. ${ }^{(25)}$ found an increase of one BMI unit associated with, on average, an increase of $0.56 \mathrm{mmHg}$ and $0.54 \mathrm{mmHg}$ in SBP and DBP, respectively, for obese children, while in non-obese children, the increase in SBP and DBP was $1.22 \mathrm{mmHg}$ and $1.20 \mathrm{mmHg}$, respectively.

The significant correlation between BP levels and BMI was also pointed out by Verma et al. ${ }^{(26)}$. Furthermore, these authors investigated which was the best determinant of BP among absolute fat mass, body fat percentage, body fat distribution and BMI, and concluded that BMI was a better predictor of BP than any other measure of body fat in nearly all analyses. In 902 healthy children and adolescents aged 5-18 years, He et al. ${ }^{(27)}$ found a significant positive relationship between SBP and DBP and trunk fat, adjusted for total fat, in boys by both dual-energy X-ray absorptiometry and skinfold measurements, while in girls trunk fat was not a significant predictor of BP. Lurbe et $a l^{(28)}$ studied a sample of 70 obese and 70 non-obese children and adolescents, aged 6-16 years, and found that SBP and DBP were significantly higher among obese subjects, while waist:hip ratio (WHR) was independently associated with SBP. Moreover, the authors pointed out that obese subjects with a predominantly abdominal fat distribution showed higher BP values and concluded that evaluation of body fat distribution in children and adolescents may help to identify subjects more likely to develop hypertension later in life. In addition, using stepwise regression analyses, Smith and Rinderknecht ${ }^{(22)}$ showed that waist circumference, age and BMI were strong predictors for SBP, while waist circumference and age were predictors for DBP in the total sample.

The aim of the present study was to investigate BP levels and their relationship with different body fat indices in a selected group of adolescents in northern Italy, in order to evaluate the prevalence of hypertension in this group of adolescents and plan preventive and corrective strategies.

\section{Methods}

\section{Participants}

In this cross-sectional study, all students attending the second year of all high schools $(n=17)$ in the Aosta Valley region (a mainly mountainous zone), northern Italy, were informed about the research protocol (number of subjects $=889$ individuals, equal to $0.74 \%$ of the entire population (120342 individuals) living in Aosta Valley region on 31 December 2001).
The population of the Aosta Valley region is equal to $0.20 \%$ of the Italian population. Five hundred and thirty-two students, 254 males (47.7\%) and 278 females $(52.3 \%)$, mean age 15.4 (SD 0.7) years (range 14,17 years), participated as volunteers in the study.

The study was carried out as part of a wider nutritional surveillance project that also included an investigation, by means of a previously validated questionnaire ${ }^{(29)}$, on adolescents' eating habits and behaviours, nutritional and food safety knowledge and dietary beliefs.

We decided to select only the second-year high-school students, as we intend to follow up the adolescents through their senior year after a preventive and corrective healthy education intervention aimed at promoting lifestyle changes, including achievement or maintenance of normal body weight, dietary habits improvement and increase in physical activity. Of the 17 high schools, nine were located in Aosta town and eight in the countryside. All students were surveyed over the course of four months, from March to the end of June 2002.

The study was carried out with the cooperation of the school teachers' board and the medical staff of the Aosta Valley Regional Public Health Department. Before starting the study, a number of meetings were organised with teachers and students to explain the aim of the research and to request their participation. Informed written consent was obtained from each student and their parents.

The research protocol was approved by the Ethics Committees of both Pavia University Medical School and the Aosta Valley Regional Public Health Department.

\section{Measurements}

\section{Body fat indices measurements}

After setting up a classroom in each school to conduct medical assessments, students were examined by trained health personnel (four physicians and one dietitian) who had received 12 hours of instruction and were standardised in assessing measurements. A subset of adolescents (57 subjects) was measured by all personnel to determine intra- and inter-operator variability, which resulted to be $<4 \%$ for all the measurements. The following parameters were measured.

- Body weight, measured on subjects wearing only underwear and without shoes, by means of a steelyard scale (precision $\pm 100 \mathrm{~g}$ ).

- Body height, measured on subjects without shoes by means of a stadiometer (precision $\pm 1 \mathrm{~mm}$ ).

- Four skinfold thicknesses (mid-triceps, mid-biceps, subscapular and suprailiac), measured on subjects according to standard conditions on the non-dominant body side using a Harpenden skinfold thickness calliper (resolution $\pm 2 \mathrm{~mm}$ ); three consecutive measurements were performed and the mean of the three values was considered. 
- Waist circumference, measured to the nearest $\mathrm{mm}$ in duplicate according to standard conditions, by placing a flexible tape midway between the lowest rib and the iliac crest. The tape was snug, but did not squeeze or compress the skin, and was parallel to the floor. The measure was collected on unclothed, relaxed subjects, after exhaling.

- Hip circumference, measured to the nearest $\mathrm{mm}$ in duplicate according to standard conditions, at the maximum extension of the buttocks with a flexible tape on the subject wearing only underwear.

BMI was calculated as the ratio between weight (in kilograms) and the square of height (in metres). The sum of the four skinfold thicknesses was computed and the body fat percentage was calculated according to the Weststrate and Deurenberg equation ${ }^{(30)}$.

\section{BP measurements}

SBP and DBP were measured according to standard conditions on the right arm, with the subject in a supine position and after resting for at least $5 \mathrm{~min}$. Measurements were made by auscultation with the use of a calibrated mercury sphygmomanometer and a cuff appropriately sized for the subject's arm size. The cuff size was chosen to be as large as possible without having the elbow skin crease obstruct the stethoscope. SBP was determined by the first Korotkoff sound, and DBP by the fifth Korotkoff sound. Three BP measurements were taken at intervals of 3-5 min and the mean of the three values was considered. $\mathrm{BP}$ was measured in the supine position because the normal percentiles of Menghetti et ll $^{(31)}$, which we used as reference standard values, were obtained by measuring $\mathrm{BP}$ in the same position.

Each student was examined and all measurements were taken during school time; each examination took about $40 \mathrm{~min}$.

\section{Smoking and alcobolic drinking babits and physical activity level}

Adolescents' smoking and alcoholic drinking habits, as well as physical activity level, were also investigated by means of an interview conducted by the trained medical staff after the measurements were taken. The interview was aimed at investigating both the number of cigarettes habitually smoked and the number and kind of alcoholic drinks habitually drunk per day or per week, as well as the number of hours of physical activity practised per day or per week.

\section{Parental investigation}

Parental weight and height, for BMI calculation, education and socio-economic levels as well as family history of hypertension were requested from the parents by means of a brief self-administered questionnaire that the students gave to their parents. Familial hypertension history was considered positive for at least one parent suffering from hypertension.

\section{Cut-off values}

In accordance with the International Obesity Task Force (IOTF), Cole et al.'s cut-off point reference standards for $\mathrm{BMI}^{(3)}$ were used to identify overweight and obesity in young age. Cole's percentile curves were drawn so that at age 18 years they passed through the widely used cut-off points of 25 and $30 \mathrm{~kg} / \mathrm{m}^{2}$ for overweight and obese adults. The resulting curves were averaged to provide age- and sex-specific cut-off points from 2 to 18 years ${ }^{(3)}$. The IOTF ${ }^{(32-34)}$ suggests that Cole's cut-off points are less arbitrary and more internationally based than current alternatives (they were developed by measuring 97876 males and 94851 females from birth to 18 years of age living in Brazil, Great Britain, Hong Kong, The Netherlands, Singapore and the USA) and will help to provide internationally comparable prevalence rates of overweight and obesity in children and adolescents.

In accordance with the report of the Fourth NHLBI (National Heart, Lung, and Blood Institute) Task Force on Blood Pressure Control in Children ${ }^{(35)}$, hypertension was diagnosed when the value of SBP and/or DBP was above the 95th reference standard percentile for age and sex, whereas levels between the 90th and the 95th percentile were considered 'high normal' (or 'borderline' or 'at risk'). Normal percentiles of Menghetti et al. ${ }^{(31)}$, constructed by fitting a third-order polynomial model of BP on age and height using multiple regression analysis, after BP measurements in 11519 healthy subjects of both sexes, aged 5-17 years, living in various locations throughout Italy, were used as the Italian reference standards.

\section{Data analysis}

Data (mean, SD) were analysed using the Statistical Package for the Social Sciences version 10 for PC (SPSS Inc., Chicago, IL, USA); they were normally distributed and Pearson's correlation coefficients were computed to analyse relationships between $\mathrm{BP}$ values and each of the adiposity indices: BMI, body fat mass, waist and hip circumferences and WHR. Multiple regression analyses with the stepwise method were used to verify the association between BP and the adiposity indices. Student's unpaired $t$ test was used to compare BP values among very active and sedentary subjects.

\section{Results}

\section{BMI and body fat indices}

Characteristics of the sample are shown in Table 1. Mean BMI was 21.9 (SD 3.4) $\mathrm{kg} / \mathrm{m}^{2}$ and 21.0 (SD 2.9) $\mathrm{kg} / \mathrm{m}^{2}$ for males and females, respectively; i.e. in the range of 
normal-weight subjects. Percentile distribution data indicated that males' BMI values were higher than those of females: $17.4 \mathrm{~kg} / \mathrm{m}^{2}$ and $16.4 \mathrm{~kg} / \mathrm{m}^{2}$ at the 5 th percentile, $21.2 \mathrm{~kg} / \mathrm{m}^{2}$ and $20.7 \mathrm{~kg} / \mathrm{m}^{2}$ at the 50 th percentile, and $28.9 \mathrm{~kg} / \mathrm{m}^{2}$ and $26.4 \mathrm{~kg} / \mathrm{m}^{2}$ at the 95 th percentile for boys and girls, respectively.

Table 2 lists the mean, sD and 5th, 50th, 95th percentile values of body fat indices for males and females. Four skinfold thicknesses, fat mass percentage, waist and hip circumferences and WHR are provided. All the measurements were statistically different between genders, with
$P$ ranging from $<0.05$ to $<0 \cdot 001$, except for hip circumference and WHR values.

\section{BP measurements}

Table 3 shows the mean, SD and percentile values of SBP and DBP for males and females, compared with the reference standard values for the Italian young population provided by Menghetti et $a l^{(31)}$. Our values were higher than the Italian reference values ${ }^{(31)}$ in both sexes. The SBP value was between the 50th and 75 th percentile

Table 1 Age and anthropometric characteristics of the sample

\begin{tabular}{|c|c|c|c|c|}
\hline \multirow[b]{2}{*}{ Variable } & \multicolumn{2}{|c|}{ Males $(n=254)$} & \multicolumn{2}{|c|}{ Females $(n=278)$} \\
\hline & Mean & SD & Mean & SD \\
\hline Age (years) & $15 \cdot 5$ & 0.7 & $15 \cdot 4$ & 0.7 \\
\hline Weight $(\mathrm{kg})$ & 65.4 & 11.5 & 55.7 & $9 \cdot 2$ \\
\hline Height (m) & 1.73 & 0.07 & 1.63 & 0.07 \\
\hline BMI $\left(\mathrm{kg} / \mathrm{m}^{2}\right)$ & 21.9 & $3 \cdot 4$ & 21.0 & $2 \cdot 9$ \\
\hline Normal-weight subjects' BMI $\left(\mathrm{kg} / \mathrm{m}^{2}\right)^{\star}$ & $21 \cdot 2$ & 2.8 & $20 \cdot 1$ & 2.5 \\
\hline Overweight subjects' BMI $\left(\mathrm{kg} / \mathrm{m}^{2}\right)^{\star}$ & 25.4 & 1.4 & $25 \cdot 6$ & 1.8 \\
\hline Obese subjects' BMI $\left(\mathrm{kg} / \mathrm{m}^{2}\right)^{\star}$ & $31 \cdot 2$ & 1.4 & $30 \cdot 7$ & 2.5 \\
\hline
\end{tabular}

SD, standard deviation; BMI, body mass index.

${ }^{*}$ Prevalence of normal weight, overweight and obesity, respectively: $74.0 \%$ (males) and $81.7 \%$ (females), $20.9 \%$ (males) and $14.7 \%$ (females), $4.7 \%$ (males) and $1.1 \%$ (females).

Table 2 Adolescents' body fat indices and percentile distribution

\begin{tabular}{|c|c|c|c|c|c|c|c|c|c|c|}
\hline \multirow[b]{3}{*}{ Variable } & \multicolumn{5}{|c|}{ Males $(n=254)$} & \multicolumn{5}{|c|}{ Females $(n=278)$} \\
\hline & \multirow[b]{2}{*}{ Mean } & \multirow[b]{2}{*}{ SD } & \multicolumn{3}{|c|}{ Percentile } & \multirow[b]{2}{*}{ Mean } & \multirow[b]{2}{*}{ SD } & \multicolumn{3}{|c|}{ Percentile } \\
\hline & & & 5th & 50th & 95th & & & 5th & 50th & 95th \\
\hline Triceps skinfold thickness (mm) & 11.6 & 5.9 & $5 \cdot 2$ & $9 \cdot 8$ & $23 \cdot 2$ & $17 \cdot 2$ & 5.4 & 9.4 & $16 \cdot 8$ & $26 \cdot 2$ \\
\hline Biceps skinfold thickness (mm) & $6 \cdot 2$ & 3.8 & 2.9 & 4.9 & 13.4 & $9 \cdot 3$ & 4.5 & $4 \cdot 2$ & 8.5 & $17 \cdot 8$ \\
\hline Subscapular skinfold thickness (mm) & $10 \cdot 0$ & $4 \cdot 3$ & $5 \cdot 8$ & $8 \cdot 8$ & $17 \cdot 7$ & $11 \cdot 6$ & 4.0 & $7 \cdot 0$ & $10 \cdot 9$ & $19 \cdot 8$ \\
\hline Suprailiac skinfold thickness $(\mathrm{mm})$ & 14.4 & 9.8 & $5 \cdot 1$ & 11.5 & $36 \cdot 4$ & $17 \cdot 1$ & $7 \cdot 8$ & $7 \cdot 7$ & $16 \cdot 0$ & 34.4 \\
\hline Body fat mass (\%) & $19 \cdot 3$ & $5 \cdot 6$ & $11 \cdot 6$ & $18 \cdot 7$ & 30.5 & 23.3 & 4.4 & $16 \cdot 1$ & 23.6 & $30 \cdot 0$ \\
\hline Waist circumference $(\mathrm{cm})$ & $75 \cdot 6$ & $10 \cdot 7$ & $66 \cdot 0$ & 74.0 & $94 \cdot 2$ & $69 \cdot 6$ & $7 \cdot 7$ & 60.5 & $69 \cdot 0$ & $84 \cdot 0$ \\
\hline Hip circumference $(\mathrm{cm})$ & $90 \cdot 7$ & $10 \cdot 5$ & 79.0 & $90 \cdot 0$ & $105 \cdot 2$ & $90 \cdot 5$ & $9 \cdot 1$ & 79.0 & $90 \cdot 0$ & $104 \cdot 0$ \\
\hline Waist:hip ratio & 0.85 & 0.36 & 0.76 & 0.83 & 0.92 & 0.79 & 0.48 & 0.70 & 0.77 & 0.85 \\
\hline
\end{tabular}

SD, standard deviation.

Table 3 Blood pressure measurements obtained in the present study compared with reference standard values of Menghetti et al. ${ }^{(31)}$

\begin{tabular}{|c|c|c|c|c|c|c|c|c|}
\hline & \multicolumn{4}{|c|}{ Present study } & \multicolumn{4}{|c|}{ Reference standard values } \\
\hline & \multicolumn{2}{|c|}{$\mathrm{SBP}(\mathrm{mmHg})$} & \multicolumn{2}{|c|}{$\mathrm{DBP}(\mathrm{mm} \mathrm{Hg})$} & \multicolumn{2}{|c|}{$\mathrm{SBP}(\mathrm{mm} \mathrm{Hg})$} & \multicolumn{2}{|c|}{$\mathrm{DBP}(\mathrm{mm} \mathrm{Hg})$} \\
\hline & M & $\mathrm{F}$ & $\mathrm{M}$ & $\mathrm{F}$ & $M$ & $\mathrm{~F}$ & M & $\mathrm{F}$ \\
\hline Mean & 124 & 118 & 76 & 75 & 117 & 111 & 70 & 66 \\
\hline \multicolumn{9}{|c|}{ Percentile } \\
\hline 5 th & 110 & 100 & 60 & 60 & 96 & 94 & 56 & 52 \\
\hline 10th & 110 & 106 & 70 & 65 & 100 & 99 & 58 & 54 \\
\hline 25th & 120 & 110 & 70 & 70 & 108 & 103 & 63 & 60 \\
\hline 50th & 120 & 120 & 80 & 78 & 113 & 112 & 70 & 67 \\
\hline 75th & 130 & 130 & 80 & 80 & 120 & 121 & 74 & 73 \\
\hline 90th & 140 & 130 & 85 & 80 & 130 & 129 & 80 & 80 \\
\hline 95th & 140 & 140 & 90 & 85 & 133 & 134 & 85 & 82 \\
\hline
\end{tabular}

SBP, systolic blood pressure; DBP, diastolic blood pressure; M, males; F, females; SD, standard deviation. 
Table 4 Prevalence rates of hypertensive subjects by gender and weight status

\begin{tabular}{|c|c|c|c|c|}
\hline & \multicolumn{2}{|c|}{ Systolic hypertensive } & \multicolumn{2}{|c|}{ Diastolic hypertensive } \\
\hline & $n$ & $\%$ & $n$ & $\%$ \\
\hline Males $(n=254)$ & 42 & $16 \cdot 5$ & 13 & $5 \cdot 1$ \\
\hline Females $(n=278)$ & 21 & 7.6 & 24 & 8.6 \\
\hline Total $(n=534)$ & 63 & 11.8 & 37 & 6.9 \\
\hline Normal-weight males $(n=188)$ & 19 & $10 \cdot 1$ & 9 & 4.8 \\
\hline Overweight plus obese males $(n=65)$ & 23 & 35.4 & 4 & $6 \cdot 1$ \\
\hline Normal-weight females $(n=227)$ & 11 & 4.8 & 21 & $9 \cdot 2$ \\
\hline Overweight plus obese females $(n=44)$ & 10 & $22 \cdot 7$ & 3 & $6 \cdot 8$ \\
\hline
\end{tabular}

in males and between the 25th and 50th percentile in females, while the DBP mean value in both sexes was between the 25 th and 50 th percentile.

Based on the Fourth Task Force Report cut-off values on hypertension ${ }^{(35)}$, in the overall sample $11.8 \%$ of the adolescents were systolic hypertensive, while $6.9 \%$ were diastolic hypertensive (Table 4). In addition, the distribution of hypertensive adolescents among normalweight subjects and overweight plus obese subjects for both sexes is provided. In males, the percentage of hypertensive adolescents was higher in the overweight plus obese subjects both for SBP and DBP compared with normal-weight subjects; in females, the percentage of hypertensive subjects was higher in the overweight plus obese subjects for SBP, while for DBP the percentage of hypertensive subjects was higher in the normal-weight subjects than in the overweight plus obese subjects.

\section{Relationships between BP levels and adiposity indices}

In the linear correlation analysis, BMI and all the adiposity indices, except WHR, were found to be significantly associated ( $P$ ranging from 0.05 to 0.001 ) with both SBP and DBP, with $r$ ranging from $0 \cdot 152$ to $0 \cdot 359$. BMI and body fat mass had the strongest association with BP. Multiple regression analyses showed that $\mathrm{BMI}$ was the strongest predictor for SBP in males $(P<0.001, r=0.275)$ and females $(P<0.001, r=0.336)$. For DBP, body fat mass was the strongest predictor only in males $(P<0.001, r=0.359)$.

\section{Parental investigation}

Adolescents' BMI correlated positively to the same extent with both the father's $(P<0 \cdot 01)$ and the mother's $(P<0.01)$ BMI in males and females, with $r$ values equal to 0.23 and $0 \cdot 24$, respectively. While BMI did not show a significant correlation with parental socio-economic and educational levels, it nevertheless showed a positive trend towards both parental low educational and low socioeconomic levels. On the other hand, both SBP and DBP values showed no correlation or trend with parental BMI, education or socio-economic level. A positive trend emerged between BP levels (either SBP or DBP) and a positive history of familial hypertension (data not shown).

\section{Smoking and alcobolic drinking babits and physical activity level}

Only 26 subjects ( $4.9 \%$ of the sample) reported being current smokers; therefore, no correlation could be carried out between BP values and smoking.

Regarding alcoholic drinking habits, only 45 subjects (8.4\%) reported being habitual consumers of two glasses of wine per day, while the consumption of other alcoholic drinks was occasional. Therefore, the number of drinking subjects was too small to carry out statistical analyses.

Finally, lower BP values emerged in very active subjects (practising physical activity for $6 \mathrm{~h}$ or more per week, $18.5 \%$ of subjects) compared with those measured in sedentary subjects (practising no habitual physical activity, $29.7 \%$ of subjects), but without any significant difference. Nevertheless, a negative trend was observed between both SBP and DBP levels and increasing physical activity practice.

\section{Discussion}

BMI data show the high prevalence of overweight subjects in both sexes, although our data are lower than those found in southern Italy ${ }^{(36-39)}$, consistent with a higher prevalence of overweight and obesity in that area. As far as body fat mass percentage is concerned, our data are higher than those reported by Schaefer et al. ${ }^{(40)}$ in a German adolescent population (12\% body fat mass for males, $21 \%$ for females) and also those reported by Ellis ${ }^{(41)}$ in a Caucasian male adolescent population (14.8\%), supporting a greater risk, mainly for males, to develop obesity, as already revealed by the higher prevalence rates of overweight and obesity in this gender.

Such a high percentage of overweight subjects is a public health threat; preventive and counteractive strategies need to be undertaken in school programmes aimed at reducing this risk condition.

With regard to body circumferences, our data are higher than those reported by other researchers in same age groups. In British adolescents waist circumference values were $70 \cdot 8$ (SD $7 \cdot 1) \mathrm{cm}$ in males and 64.9 (SD 4.9$) \mathrm{cm}$ in females ${ }^{(42)}$. In Cuba the 50 th percentile waist circumference values were equal to $68 \mathrm{~cm}$ for males and 
$64 \mathrm{~cm}$ for females ${ }^{(43)}$. On the other hand, our data are supported by studies carried out in the $\mathrm{USA}^{(42)}$ and Spain $^{(44)}$ (50th percentile waist circumference values equal to $74 \mathrm{~cm}$ for males and $69 \mathrm{~cm}$ for females), showing that our population is more similar to these ones.

The present SBP and DBP values are higher (Table 5) than those reported as Italian reference standards ${ }^{(31)}$ for a young population aged 15 years. Concerning Menghetti et al.'s data ${ }^{(31)}$, they show that Italian children's and adolescents' BP levels are slightly higher than those of Americans, in contrast with the belief that Italian people are protected against cardiovascular risk factors, including hypertension, more than other populations.

Our values are higher than those found some years ago by Maida et al. $^{(45)}$ in Sardinian adolescents aged 11-15 years and higher than those reported by Paradis et al. ${ }^{(46)}$ in Canadian adolescents aged 16 years. On the other hand, they are quite similar to those found in 1526 Belgian adolescents ${ }^{(47)}$, aged $12-17$ years, who had been selected from a high cardiovascular risk population. Even the 50th percentile values are higher than those reported in Brazilian adolescents of the same age ${ }^{(48)}$.

The SBP and DBP 90th percentile values found in males in the present study are higher than those in the USA ${ }^{(31)}$ $(128 / 79 \mathrm{mmHg})$ and in northern Europe ${ }^{(31)}(137 / 77 \mathrm{mmHg})$ in the same age group, while in females they are similar $\left(126 / 80 \mathrm{mmHg}\right.$ in the $\mathrm{USA}^{(31)}$ and $130 / 76 \mathrm{mmHg}$ in northern Europe $\left.^{(31)}\right)$. In males, the SBP 90th percentile value is particularly high $(140 \mathrm{mmHg}$ ); it is even equal to the value considered as an indicator of first-degree hypertension in the adult population. These values in males may be due to the high prevalence rates of overweight and obesity, as well as the high values of adiposity indices, which are well-known risk factors for hypertension.

The prevalence rates of systolic and diastolic hypertensive adolescents are high, but they are mostly related to SBP (11.8\% of subjects). Comparison of our data with others' (Table 6) shows higher values than those in adolescent populations of different ages and in different geographical areas ${ }^{(23,49-52)}$.

Higher prevalence rates of hypertensive adolescents in overweight plus obese subjects (Table 4), when compared with normal-weight subjects, support previous findings ${ }^{(18-23,53)}$ reporting that high BMI values are a predisposing factor in the development of hypertension. Nevertheless, the percentage of hypertensive subjects found even in the group of normal-weight subjects, consistent with other studies ${ }^{(24,25)}$, shows that hypertension is an under-recognised clinical entity in children and adolescents, while monitoring of BP levels might help in detecting occult hypertension at a young age and limiting the magnitude of cardiovascular risk. Indeed, hypertension is the most common form of cardiovascular disease and it is often associated with overweight and obesity. Although it is less common in adolescents than in adults, hypertension and the associated organ damage can and often do begin early in life. Unless reversed, this condition could determine cardiovascular disease outcome in adulthood. Consequently, for many with high BP levels, measures directed at the long-term prevention of cardiovascular morbidity may need to be started in adolescence to achieve maximal effectiveness.

Table 5 Mean blood pressure values in the present sample compared with those found in other adolescent groups

\begin{tabular}{|c|c|c|c|c|}
\hline & \multicolumn{2}{|c|}{$\mathrm{SBP} / \mathrm{DBP}(\mathrm{mmHg})$} & \multirow[b]{2}{*}{ Adolescents' age (years) } & \multirow[b]{2}{*}{ Reference } \\
\hline & $M$ & $\mathrm{~F}$ & & \\
\hline Our sample & $124 / 76$ & $118 / 75$ & 15 & Present study \\
\hline Italian reference standards & $117 / 70$ & $111 / 66$ & 15 & Menghetti et al. $(1999)^{(31)}$ \\
\hline Sardinia (Italy) & $104 / 42$ & $109 / 44$ & $11-15$ & Maida et al. (1982)(45) \\
\hline Quebec (Canada) & $124 / 61$ & $114 / 62$ & 16 & Paradis et al. $(2004)^{(46)}$ \\
\hline Luxembourg (Belqium) & $125 / 74$ & $122 / 74$ & $12-17$ & Paulus et al. (1999)(47) \\
\hline Rio de Janeiro (Brazil) & $117 / 61^{*}$ & $110 / 62^{*}$ & 15 & Pozzan et al. $(1997)^{(48)}$ \\
\hline
\end{tabular}

SBP, systolic blood pressure; DBP, diastolic blood pressure; M, males; F, females.

*50th percentile values.

Table 6 Prevalence rates of systolic hypertensive adolescents (males plus females) in the present sample compared with those found in other young groups

\begin{tabular}{|c|c|c|c|c|}
\hline & \multirow[b]{2}{*}{ Prevalence rate (\%) } & \multicolumn{2}{|c|}{ Age (years) } & \multirow[b]{2}{*}{ Reference } \\
\hline & & Mean & SD & \\
\hline Our sample & $11 \cdot 8$ & \multirow{2}{*}{\multicolumn{2}{|c|}{$11-14+$}} & Present study \\
\hline Rome (Italy) & 6.5 & & & Menghetti et al. (2004) ${ }^{(49)}$ \\
\hline Maceio (Brazil) & 9.4 & $12 \cdot 4$ & 2.9 & Moura et al. $(2004)^{(50)}$ \\
\hline Corrients City (Spain) & 3.0 & 14.8 & 1.6 & Martinez et al. $(2001)^{(23)}$ \\
\hline Debrecen (Hungary) & 2.5 & \multirow{2}{*}{\multicolumn{2}{|c|}{$\begin{array}{l}15-18 t \\
11-17 t\end{array}$}} & Pall et al. $(2005)^{(51)}$ \\
\hline Ludhiana (India) & $6 \cdot 7 / 2 \cdot 6^{\star}$ & & & Mohan et al. (2004) \\
\hline
\end{tabular}

SD, standard deviation.

${ }^{*}$ In urban/rural areas.

tAge range (years). 
Even though BMI and all the adiposity indices were found to be significantly associated with BP levels in both sexes, BMI and body fat mass showed the strongest association, most closely related to SBP in both genders and to DBP only in males, in agreement with the literature data indicating that BMI contributes significantly to BP variability $^{(19-21,24,27,46)}$, even in non-obese subjects ${ }^{(24,25)}$.

The correlation between parental and adolescents' BMI values supports previous findings ${ }^{(18,54-56)}$ showing an influence of both parents' BMI on their children. In particular, the results are in agreement with the data obtained in a previous study carried out in southern Italy ${ }^{(57)}$ in which children's BMI correlated with both fathers' and mothers' BMI to the same extent.

Although no significant correlation between adolescents' BMI and parental socio-economic and education levels emerged, a positive trend was found showing that these factors may influence weight condition, as reported by other authors ${ }^{(54,58)}$. In addition, adolescents' risk of becoming overweight increased with parental overweight and obesity, thus showing that familial condition (genetics, unhealthy dietary habits together with a sedentary lifestyle) has to be taken into account to identify risk groups for preventive measures. It is interesting to point out that foods such as cheese rich in fats, salami, sausages, butter and lard are traditional components of local meals in this region (data not presented).

Parental BMI does not seem to influence children's BP levels in our sample; it is more likely that parental history of hypertension, rather than parental BMI, may influence children's BP levels since a positive trend emerged between students' BP levels and a positive history of familial hypertension. Neither parental socio-economic level nor education level influenced children's BP levels in our study.

The data reported by the students about smoking are doubtful since a recent investigation ${ }^{(59)}$ showed an increase of smokers among adolescents aged 14-16 years equal to $33 \%$ in males and $69 \%$ in females during a six-year period (1993-1999).

The fact that 45 subjects report being habitual consumers of two glasses of wine per day is not surprising, since alcohol consumption is widespread in this region, while we expected more physical activity practice in a mainly mountainous zone. Despite this, a negative trend was observed between BP levels and increasing physical activity practice, confirming the positive role of habitual physical activity in preventing hypertension.

\section{Conclusion}

The limitation of this study arises from the fact that we examined subjects of a selected age group and therefore the results may not be extended to a wider range of adolescents, even though we explained the reason for our choice.
The high values of BP and hypertension rates, together with high prevalence of overweight plus obese subjects found in our sample, are worrying. There is a pressing need to develop a comprehensive medical and nutrition plan together with preventive and corrective strategies in school programmes to reduce the prevalence of these identified disease states, by empowering teens to increase physical activity and to improve their own dietary habits together with their lifestyle.

\section{Acknowledgements}

The authors of this paper state that: there are no financial or other contractual agreements that might cause conflicts of interest; the research obtained funding from the Italian Ministry of Health; and each author has participated actively in the work and has given substantial contribution: G.T. - project of the study, data analysis and supervisor; R.B. - supervisor in the assessment of anthropometric measurements; L.M. - statistical analysis; C.R. - supervisor. The Italian Ministry of Health is thanked for funding the research.

\section{References}

1. World Health Organization (1998) Obesity: Preventing and Managing the Global Epidemic. Report of a WHO Consultation, Geneva, 3-5 June 1997. Geneva: WHO.

2. Pi-Sunyer FX, Laferrère B, Aronne LJ \& Bray GA (1999) Therapeutic controversy: obesity - a modern day epidemic. J Clin Endocrinol Metab 84, 3-12.

3. Cole TJ, Bellizzi MC, Flegal KM \& Dietz WH (2000) Establishing a standard definition for child overweight and obesity worldwide: international survey. BMJ 320, $1240-1243$.

4. World Health Organization (2003) Global Strategy on Diet, Physical Activity and Health. http://www.who.int/ dietphysicalactivity/en/ (accessed September 2007).

5. Livingstone B (2000) Epidemiology of childhood obesity in Europe. Eur J Pediatr 159, Suppl. 1, S14-S34.

6. Parsons TJ, Power C, Logan S \& Summerbell CD (1999) Childhood predictors of adult obesity: a systematic review. Int J Obes Relat Metab Disord 23, Suppl. 8, S1-S107.

7. Kiess W, Reich A, Muller G, Meyer K, Galler A, Bennek J \& Kratzsch J (2001) Clinical aspects of obesity in childhood and adolescence - diagnosis, treatment and prevention. Int J Obes Relat Metab Disord 25, Suppl. 1, S75-S79.

8. Burke V, Beilin LJ \& Dunbar D (2001) Tracking of blood pressure in Australian children. J Hypertens 19, 1185-1192.

9. Chu NF, Wang DG \& Shieh SM (2001) Obesity, leptin and blood pressure among children in Twain: the Taipei children's heart study. Am J Hypertens 14, 135-140.

10. McGill HC Jr, McMahan CA, Malcolm GT, Oalmann MC \& Strong JP (1995) The Pathobiological Determinants of Atherosclerosis in Youth (PDAY) Research Group. Relation of glycohemoglobin and adiposity to atherosclerosis in youth. Arterioscler Thromb Vasc Biol 15, 431-440.

11. Srinivasan SR, Meyers L \& Berenson GS (2001) Rate of change in adiposity and its relationship to concomitant changes in cardiovascular risk variables among biracial (black-white children) and young adults: the Bogalusa heart study. Metabolism 50, 299-305. 
12. Geiss HC, Parhofer KG \& Schwandt P (2001) Parameters of childhood obesity and their relationship to cardiovascular risk factors in healthy prepubescent children. Int J Obes Relat Metab Disord 25, 830-837.

13. Frontini MG, Bao W, Elkasabany A, Srinivasan SR \& Berenson G (2001) Comparison of weight-for-height indices as a measure of adiposity and cardiovascular risk from childhood to young adulthood. J Clin Epidemiol 54, 817-822.

14. Young-Hyman D, Schlundt DG, Herman L, De Luca F \& Counts D (2001) Evaluation of the insulin resistance syndrome in 5- to 10-year-old overweight/obese AfricanAmerican children. Diabetes Care 24, 1359-1364.

15. Pinhas-Hamiel O, Dolan LM, Daniels SR, Standiford D, Khoury PR \& Zeitler P (1996) Increased incidence of noninsulin-dependent diabetes mellitus among adolescents. J Pediatr 128, 608-615.

16. Power C, Lake JK \& Cole TJ (1997) Measurements of longterm health risks of child and adolescent fatness. Int J Obes Relat Metab Disord 21, 507-526.

17. Maffeis C \& Tato L (2001) Long-term effects of childhood obesity on morbidity and mortality. Horm Res 55, Suppl. 1, 42-45.

18. Buonomo E, Pasquarella A \& Palombi L (1996) Blood pressure and anthropometry in parents and children of a southern Italian village. J Hum Hypertens 10, Suppl. 3, S77-S79.

19. Leccia G, Marotta T, Masella MR, Mottola G, Mitrano G, Golia F, Capitanata P, Guida L, Contaldo F \& Ferrara LA (1999) Sex-related influence of body size and sexual maturation on blood pressure in adolescents. Eur J Clin Nutr 53, 333-337.

20. Koziel S, Kolodziej H \& Ulijaszek S (2001) Body size, fat distribution, menarcheal age and blood pressure in 14-year-old girls. Eur J Epidemiol 17, 1111-1115.

21. Uscategui Penuela RM, Perez Giraldo JA, Aristizabal Rivera JC \& Camacho Perez JA (2003) Excess of weight and their relationship with high blood pressure in schoolchildren and adolescents of Medellin, Colombia. Arch Latinoam Nutr 53, 376-382.

22. Smith C \& Rinderknecht K (2003) Obesity correlates with increased blood pressures in urban native American youth. Am J Hum Biol 15, 78-90.

23. Martinez CA, Ibanez JO, Paterno CA, De Roig Bustamante MS, Itati Heitz M, Kriskovich Jure JO, De Bonis GR \& Cáceres LC (2001) Overweight and obesity in children and adolescents of Corrients city. Relationship with cardiovascular risk factors. Medicina (B Aires) 61, 308-314.

24. Reich A, Müller G, Gelbrich G, Deutscher K, Gödicke R \& Kiess W (2003) Obesity and blood pressure - results from the examination of 2365 schoolchildren in Germany. Int J Obes Relat Metab Disord 27, 1459-1464.

25. He Q, Ding ZY, Fong DY \& Karlberg J (2000) Blood pressure is associated with body mass index in both normal and obese children. Hypertension 36, 165-170.

26. Verma M, Chhatwal J \& George SM (1995) Biophysical profile of blood pressure in school children. Indian Pediatr 32, 749-754.

27. He Q, Horlick M, Fedun B, Wang J, Pierson RN Jr, Heshka S \& Gallagher D (2002) Trunk fat and blood pressure in children through puberty. Circulation 105, 1093-1098.

28. Lurbe E, Alvarez V, Liao Y, Tacons J, Cooper R, Cremades B, Torro I \& Redón J (1998) The impact of obesity and body fat distribution on ambulatory blood pressure in children and adolescents. Am J Hypertens 11, 418-424.

29. Turconi G, Celsa M, Rezzani C, Biino G, Sartirana MA \& Roggi C (2003) Reliability of a dietary questionnaire on food habits, eating behaviour and nutritional knowledge of adolescents. Eur J Clin Nutr 57, 753-763.
30. Weststrate JA \& Deurenberg P (1989) Body composition in children: proposal for a method for calculating body fat percentage from total body density or skinfold thickness measurements. Am J Clin Nutr 50, 1104-1115.

31. Menghetti E, Virdis R, Strambi M, Patriarca V, Riccioni MA, Fossali E \& Spagnolo A (1999) Blood pressure in childhood and adolescence: the Italian normal standards. Study group on Hypertension of the Italian Society of Pediatrics. J Hypertens 17, 1363-1372.

32. Bellizzi MC \& Dietz WH (1999) Workshop on childhood obesity: summary of the discussion. Am J Clin Nutr 70, 173S-175S

33. Dietz WH \& Robinson TN (1998) Use of the body mass index (BMI) as a measure of overweight in children and adolescents. J Pediatr 132, 191-193.

34. International Obesity Task Force (2003) Establishing a standard definition for child overweight and obesity worldwide: international survey. In Childhood Obesity. http://www.iotf.org/childhoodobesity.asp (accessed September 2007).

35. National High Blood Pressure Education Program Working Group on High Blood Pressure in Children and Adolescents (2004) The fourth report on the diagnosis, evaluation, and treatment of high blood pressure in children and adolescents. Pediatrics 114, 2 Suppl. 4th Report, 555-576.

36. Grispan A, Toselli S, Fabiani M, Bontempo V, Liberatore S, Gagliardi C \& Tarsitani G (1997) Prevalenza dell'obesità in età evolutiva Nota 2: studio epidemiologico nelle scuole medie inferiori di L'Aquila. Ann $\operatorname{Ig}$ 9, 119-125.

37. De Vito E, La Torre G, Langiano E, Berardi D \& Ricciardi G (1999) Overweight and obesity among secondary school children in Central Italy. Eur J Epidemiol 15, 649-654.

38. Romiti A, Salandri A, Imbrogno N, De Angelis G, Ferraro A \& Di Mario U (2000) Prevalence of obesity in adolescence. Clin Ter 151, 335-339.

39. D'Argenio P, Citarella A, Palombi EL, Aversano MP, Bassi R, Di Fiore A. (2001) Obesità e sovrappeso tra i preadolescenti. Uno studio dalla provincia di Benevento. BEN-Notiziario ISS 14(1); available at http://www.ben. iss.it/precedenti/gennaio/2.htm

40. Schaefer F, Georgi M, Wuhl E \& Scharer K (1998) Body mass index and percentage fat mass in healthy German schoolchildren and adolescents. Int J Obes Relat Metab Disord 22, 461-469.

41. Ellis KJ (2000) Human body composition: in vivo methods. Physiol Rev 80, 649-680.

42. McCarthy HD, Jarrett KV \& Crawley HF (2001) The development of waist circumference percentiles in British children aged 5.0-16.9 y. Eur J Clin Nutr 55, 902-907.

43. Martinez E, Devesa M, Bacallao J \& Amador M (1994) Percentiles of the waist-hip ratio in Cuban scholars aged 4.5 to 20.5 y. Int J Obes Relat Metab Disord 18, 557-560.

44. Moreno LA, Fleta J, Mur L, Rodriguez G, Sarria A \& Bueno M (1999) Waist circumference values in Spanish children gender-related differences. Eur J Clin Nutr 53, 429-433.

45. Maida A, Mura I, Muresu E \& Romano G (1982) Obesity and humoral and pressure indicators in a sample population between 6 and 20 years of age from the province of Sassari. Nuovi Ann Ig Microbiol 33, 637-654.

46. Paradis G, Lambert M, O'Loughlin J, Lavallee C, Aubin J, Delvin E, Levy E \& Hanley JA (2004) Blood pressure and adiposity in children and adolescents. Circulation 110, 1832-1838.

47. Paulus D, Saint-Remy A \& Jeanjean M (1999) Blood pressure during adolescence: a study among Belgian adolescents selected from a high cardiovascular risk population. Eur J Epidemiol 15, 783-790.

48. Pozzan R, Brandao AA, Da Silva SL \& Brandao AP (1997) Hyperglycemia, hyperinsulinemia, overweight, and high 
blood pressure in young adults: the Rio de Janeiro Study. Hypertension 30, 650-653.

49. Menghetti E, D’Addesa D, Censi L, Spagnolo A, Martone D, Cellitti R \& Sette S (2004) Hypertension in schoolchildren: research carried out in a secondary school in Rome and observations on dietary patterns. Minerva Pediatr 56, 311-316.

50. Moura AA, Silva MA, Ferraz MR \& Rivera IR (2004) Prevalence of high blood pressure in children and adolescents from the city of Maceio, Brazil. J Pediatr (Rio J) 80, 35-40.

51. Pall D, Katona E, Paragh G, Zrinyi M, Zatik J \& Fulesdi B (2005) Epidemiological data of 15-18 year adolescents and the prevalence of hypertension in Debrecen. The Debrecen hypertension study. Orv Hetil 146, 127-132.

52. Mohan B, Kumar N, Aslam N, Rangbulla A, Kumbkarni S, Sood NK \& Wander GS (2004) Prevalence of sustained hypertension and obesity in urban and rural school going children in Ludhiana. Indian Heart J 56, 310-314.

53. Burke V, Beilin LJ, Dunbar D \& Kevan M (2004) Associations between blood pressure and overweight defined by new standards for body mass index in childhood. Prev Med 38, 558-564.
54. Krassas GE, Tzotzas T, Tsametis C \& Konstantinidis T (2001) Determinants of body mass index in Greek children and adolescents. J Pediatr Endocrinol Metab 14, Suppl. 5, S1327-S1333.

55. Pietilainen KH, Kaprio J, Rasanen M, Winter T, Rissanen A \& Rose RJ (2001) Tracking of body size from birth to late adolescence: contributions of birth length, birth weight, duration of gestation, parents' body size, and twinship. Am J Epidemiol 154, 21-29.

56. Burke V, Beilin LJ \& Dunbar D (2001) Family lifestyle and parental body mass index as predictors of body mass index in Australian children: a longitudinal study. Int J Obes Relat Metab Disord 25, 147-157.

57. Esposito-Del Puente A, Scalfi L, De Filippo E et al. (1994) Familial and environmental influences on body composition and body fat distribution in childhood in Southern Italy. Int J Obes Relat Metab Disord 18, 596-601.

58. McMurray RG, Harrell JS, Deng S, Bradley CB, Cox LM \& Bangdiwala SI (2000) The influence of physical activity, socioeconomic status, and ethnicity on the weight status of adolescents. Obes Res 8, 130-139.

59. Istituto Superiore di Sanità, Italy (2003) I dati sul fumo. http://www.epicentro.iss.it/temi/fumo/dati.asp (accessed September 2007). 